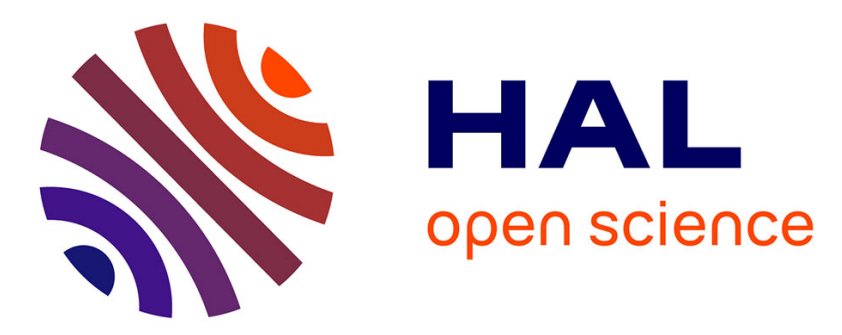

\title{
Idiopathic pulmonary fibrosis Significance of the usual interstitial pneumonia (UIP) CT-scan patterns defined in new international guidelines
}

T. Diridollou, L. Sohier, Chloé Rousseau, A. Angibaud, P. Chauvin, T. Gaignon, M. Tas, J. Lemerre, M. Kerjouan, A. Salé, et al.

\section{To cite this version:}

T. Diridollou, L. Sohier, Chloé Rousseau, A. Angibaud, P. Chauvin, et al.. Idiopathic pulmonary fibrosis Significance of the usual interstitial pneumonia (UIP) CT-scan patterns defined in new international guidelines. Respiratory Medicine and Research, 2020, 77, pp.72-78. 10.1016/j.resmer.2020.02.004 . hal-02862832

HAL Id: hal-02862832

https://hal-univ-rennes1.archives-ouvertes.fr/hal-02862832

Submitted on 12 Jun 2020

HAL is a multi-disciplinary open access archive for the deposit and dissemination of scientific research documents, whether they are published or not. The documents may come from teaching and research institutions in France or abroad, or from public or private research centers.
L'archive ouverte pluridisciplinaire HAL, est destinée au dépôt et à la diffusion de documents scientifiques de niveau recherche, publiés ou non, émanant des établissements d'enseignement et de recherche français ou étrangers, des laboratoires publics ou privés. 


\title{
Idiopathic pulmonary fibrosis: significance of the usual interstitial pneumonia (UIP) CT-scan patterns defined in new international guidelines
}

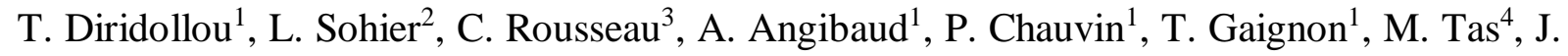

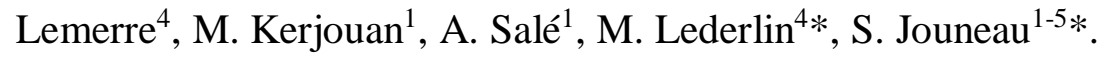

*Both authors contributed equally.

\section{Affiliations:}

1. Service de Pneumologie, Centre de Compétences pour les Maladies Rares Pulmonaires, CHU de Rennes, France ; Université de Rennes 1, Rennes, France

2. Service de Pneumologie, centre hospitalier Lorient, Lorient, France

3. Centre d'Investigation Clinique, Inserm 1414, Rennes, France.

4. Service de Radiologie, CHU de Rennes, France ; Université de Rennes 1, Rennes, France

5. UMR1085, IRSET, Université de Rennes 1, Rennes, France Adresse électronique: stephane.jouneau@chu-rennes.fr

\section{Correspondance:}

Thomas Diridollou,

Centre Hospitalier Universitaire de Rennes, Service de Pneumologie,

Centre de Compétences pour les Maladies Rares Pulmonaires,

2 rue Henri Le Guilloux, 35033 Rennes Cedex 9, France.

E-mail: thomas.diridollou@gmail.com

Tel: +33633074629

\begin{abstract}
Introduction. The new 2018 international guidelines for diagnosing usual interstitial pneumonia (UIP)/idiopathic pulmonary fibrosis (IPF) by CT scan split the old pattern possible UIP (2011 IPF guidelines) into two new patterns: probable UIP and indeterminate for UIP.
\end{abstract} However, the proportions and prognoses of these new CT-scan patterns are not clear. 
Methods. We used a monocentric retrospective cohort of 322 patients suspected of having IPF (University Hospital of Rennes; Competence Center for Rare Lung Diseases; 1 January 201231 December 2017). All patients initially diagnosed by CT scan as possible UIP were included. The chest CT-scans were then reclassified according to the new 2018 international guidelines by 3 observers. These data were then subjected to survival analysis with multivariate Cox regression using a composite endpoint of death, lung transplantation, a decline of $\geq 10 \%$ in forced vital capacity (FVC), or hospitalization.

Results. Of the 89 possible UIP patients included, 74 (83\%) were reclassified as probable UIP and 15 (17\%) as indeterminate for UIP. Probable UIP patients were more likely to meet the composite endpoint (56/74 [75.7\%] vs. 5/15 [33\%] patients; HR [IC 95\%] = 3.12 [1.24 ; 7.83], $\mathrm{p}=0.015$ ). Multivariate analysis indicated that the probable UIP pattern was associated with significantly increased risk of reaching the composite endpoint $(\mathrm{HR}[95 \% \mathrm{CI}]=2.85[1.00$; 8.10], $\mathrm{p}=0.049)$.

Conclusion. The majority of possible UIP diagnoses corresponded to probable UIP, which was associated with a significantly worse prognosis than indeterminate for UIP. This distinction between these two CT patterns emphasizes the relevance of the new international guidelines for the diagnosis of IPF.

Keywords: interstitial lung disease, computed tomography, prognostic factors, outcomes, nintedanib, pirfenidone

\section{Introduction}

Idiopathic pulmonary fibrosis (IPF) is a diffuse interstitial lung disease (ILD) associated with a CT-scan and/or histopathological pattern of usual interstitial pneumonia (UIP) (1) that is chronic, gradually worsens and is incurable (excluding lung transplantation) (2). Some patients experience a slow gradual decline in respiratory function, while in others the disease worsens very rapidly during acute exacerbations or "flare-ups" (2). The median survival of all patients with IPF is 3 years from diagnosis (2). Chest CT-scan is now prominent in the management of those patients, in order to obtain an accurate, early diagnosis needed for treatment with the anti-fibrotic drug that have recently become available $(3,4)$. 
The 2011 IPF international guidelines identified three degrees of diagnostic certainty for UIP assessed with a CT-scan: typical UIP, possible UIP, and inconsistent with UIP (5). However, the possible UIP pattern was problematic because it included a large proportion of patients, who theoretically had to be subjected to potentially dangerous surgical biopsy (5). The data accumulated over the past 15 years have led to the possible UIP CT-scan pattern being divided into probable UIP and indeterminate for UIP, with biopsy being less frequent in the probable UIP patients (6). The Fleischner Society's White Paper and the new IPF international guidelines have established four CT-scan categories: typical UIP, probable UIP, indeterminate for UIP and alternative diagnosis (6,7). Chest CT-scans previously classified as possible UIP are now classified as probable UIP or indeterminate for UIP.

However, the frequency of distribution of probable UIP and indeterminate for UIP within the former possible UIP pattern is not known precisely, and only few data are available on the prognoses of these two new CT-scan patterns (8). Therefore, we analyzed retrospectively the clinical, functional, radiological and prognostic differences between the possible UIP patients reclassified as probable UIP or indeterminate for UIP.

\section{Methods}

\section{Design and study population.}

This retrospective, monocentric cohort study was conducted in the Pulmonology Department of the University Hospital of Rennes (Competences Center for Rare Pulmonary Diseases). It included all patients suspected of having IPF and initially diagnosed by CT-scan as possible UIP in multidisciplinary discussion (MDD), between 1 January 2012 and 31 December 2017. Patients with known causes of ILD (occupational or environmental exposure, systemic disease, or drug toxicity) were not eligible. The MDD followed the 2011 IPF international guidelines throughout the inclusion period (5).

The study was approved by the ethics committee of the University Hospital of Rennes $\left(n^{\circ} 19.82\right)$.

\section{Data collection.}

Demographic (gender, age), clinical (comorbidities, dyspnea, tobacco use, performance of surgical lung biopsy), and functional data at the time of diagnosis were obtained from the hospital computerized medical records. The Charlson comorbidity score was calculated (9). Dyspnea was assessed using the New York Heart Association (NYHA) scale. Pulmonary 
functional tests (PFTs) were performed according to international recommendations $(10,11)$. The gender age physiology (GAP) score was calculated as proposed by Ley et al (12).

Prognosis data, including death/lung transplantation, functional decline, hospitalization, were obtained for all patients from the hospital medical records and verified with each patient's general practitioner at the end of the analysis (April 2019). No patients were lost to follow-up.

\section{Radiological evaluation.}

The initial chest CT-scans of all patients were analyzed by 2 independent experienced observers (T.D. and L.S.), blinded to all clinical and histological data. All discrepancies were reviewed by a third observer (M.L.) and a consensus was reached. Chest CT-scans were reclassified according to the new international guidelines (7). Briefly, the CT features of the probable UIP pattern are subpleural and basal reticulations with peripheral traction bronchiectasis or bronchiolectasis (TB). Mild ground glass opacity might be present. The CT features of the indeterminate for UIP pattern are subpleural and basal subtle reticulations ("early UIP pattern") or lung fibrosis that do not suggest any specific etiology ("truly indeterminate") (7). The total disease extent, $+/-5 \%$, was calculated for each patient (13). The presence of peripheral TB and five interstitial features (reticulations, ground glass opacities, honeycombing, condensations, mosaic attenuation) and emphysema, based on the Fleischner Society glossary (14), was assessed (presence/ absence) for each patient.

\section{Statistical analysis.}

The quantitative variables normally distributed were reported as $\mathrm{N}$, mean, standard deviation. Groups were compared by Student's $t$ test. GAP score was the only quantitative variable not normally distributed. Thus it was reported by $\mathrm{N}$, median, interquartile range. Groups were compared by the non-parametric Mann-Whitney U-test. The number (N) and percentage (\%) are given for each modality of qualitative variables. These groups were compared using the $\mathrm{Chi}^{2}$ parametric test or Fisher's non-parametric test.

Survival was analyzed using a composite endpoint: time from initial MDD assessment to the first occurrence of all-cause death, lung transplantation, a decline of $\geq 10 \%$ in absolute forced vital capacity (FVC), or all-cause hospitalization (15-17). Patients who did not report events were censored at the end of the analysis (30 April, 2019). Each component of the composite endpoint was evaluated independently using the total number of events observed during followup. Kaplan-Meier curves were prepared and compared using a log-rank test. The variables ( $\mathrm{p}<$ 
0.20) identified by univariate survival analysis with a Cox model were included in a multivariate model, which was followed by stepwise top-down selection.

All statistical tests (two-tailed $\mathrm{p}<0.05$ ) were performed with SAS software, version 9.4.

\section{Results}

\section{Study population.}

Overall, 89 patients were included (mean age 72.8 \pm 8.2 years; 72 (80.9\%) male) (Figure 1). Their characteristics are summarized in Table 1.

\section{CT-scan Features}

Of these 89 patients, $74(83 \%)$ were reclassified with a probable UIP pattern (probable UIP group), and 15 (17\%) with an indeterminate UIP pattern (indeterminate UIP group) (Table 1) (Figures 2-4). Probable UIP patients had more extensive disease and more frequent peripheral TB compared with indeterminate UIP patients (44.8\% vs. $29.7 \%, \mathrm{p}=0.006$ and 74/74 [100.0\%] vs. 7/15 [46.7\%], p<0.001, respectively). Indeterminate UIP could be divided in 8 "early UIP pattern" and 7 "truly indeterminate". Emphysema lesions were more common in the indeterminate UIP group ( $\mathrm{p}=0.03)$ (Figure 4$)$.

\section{Demographic, clinical and functional characteristics}

There was no difference in the age, sex, or Charlson comorbidity score between the groups (Table 1). More patients were smokers in the indeterminate UIP group $(13 / 15 ; 86.7 \%)$ than in the probable UIP group $(38 / 74 ; 52.8 \%)(\mathrm{p}=0.015)$. Numerically, more probable UIP patients $(31 / 34 ; 91 \%)$ displayed typical or probable UIP pathology than did the indeterminate UIP patients $(5 / 7 ; 71 \%) \mathrm{p}=0.196)$. In the indeterminate for UIP group, alternative pathological diagnoses were possible UIP $(n=1)$, hypersensitivity pneumonitis $(n=2)$, and organized pneumonia $(\mathrm{n}=2)$. Impaired pulmonary function was more severe in probable UIP patients than in indeterminate UIP patients, with greater NYHA dyspnea $(2.2 \pm 1.1 \mathrm{vs} .1 .1 \pm 1.0, \mathrm{p}<0.001)$, lower FVC $(85.2 \pm 17.3 \%$ vs. $103.7 \pm 18.6 \%$, p <0.001), lower pulmonary carbon monoxide transfer (TLCO) $(50.3 \pm 16.3 \%$ vs. $65.0 \pm 14.0 \%, \mathrm{p}=0.01)$ and a higher GAP score (4.0 [3.0; 5.0] vs. $3.0[2.0 ; 4.0], \mathrm{p}=0.04)$. 


\section{Evolution}

The mean follow-up period of the probable UIP group was $23.7 \pm 15.8$ months; it was 32.3 \pm 20.5 months for the indeterminate UIP group $(\mathrm{p}=0.071)$. More probable UIP patients $(56 / 74$; $75.7 \%$ ) met one of the composite endpoint events than did the indeterminate for UIP patients $(5 / 15 ; 33 \%$, HR [IC 95\%] $=3.12$ [1.24; 7.83], p=0.015) (Figure 5A). The median composite endpoint-free survival of the probable UIP patients was 22.5 months, while that of the indeterminate UIP group was not reached (Figure 5A).

Significantly more probable UIP patients $(32 / 74 ; 43.2 \%)$ died or had lung transplants than did the indeterminate UIP patients $(2 / 15 ; 13.3 \%$, HR [IC 95\%] $=4.66[1.11 ; 19.61], \mathrm{p}=0.035)$. The median lung transplant-free survival time was 46.2 months in the probable UIP group and was not reached by any of the indeterminate UIP group (Figure 5B). Significantly more probable UIP patients $(35 / 64 ; 54.7 \%)$ demonstrated $\mathrm{a} \geq 10 \%$ decline in FCV than did those in the indeterminate UIP group $(2 / 12 ; 16.7 \%, \mathrm{HR}[\mathrm{IC} 95 \%]=4.28[1.03 ; 17.84], \mathrm{p}=0.045)$ (Figure 5C). No significant difference was seen between the groups for all-cause hospitalizations $(38 / 66 ; 57.6 \%$ and 3/11; 27.3\%, HR [IC 95\%] $=2.39[0.74 ; 7.76], \mathrm{p}=0.145)$ (Figure 5D).

Univariate analysis indicated that the parameters significantly associated with the composite endpoint were: FVC \% predicted value $(\mathrm{p}=0.001)$, TLCO $\%$ predicted value $(\mathrm{p}<0.0001)$, GAP score $(\mathrm{p}=0.01)$, probable UIP CT pattern $(\mathrm{p}=0.015)$, total CT disease extent $(\mathrm{p}=0.004)$ (Table 2). Multivariate analysis showed that only TLCO $(\mathrm{HR}[95 \% \mathrm{CI}]=0.73[0.61 ; 0.88], \mathrm{p}<0.001)$ and a probable UIP CT-scan pattern $(\mathrm{HR}[95 \% \mathrm{CI}]=2.85[1.00 ; 8.10], \mathrm{p}=0.049)$ were significantly associated with the composite endpoint (Table 2).

\section{Discussion}

In this study, we reclassified $83 \%$ of the patients having an initial possible UIP CT pattern (2011 IPF guidelines) (5) as probable UIP (2018 IPF guidelines) (7); the remaining 17\% were assigned to the indeterminate for UIP category (2018 IPF guidelines) (7). The probable UIP CT pattern was associated with more severe functional impairment at diagnosis, an increased risk of death, lung transplantation, and a decline in FVC during follow-up than was the indeterminate for UIP pattern. The median lung transplant-free survival time of 46.2 months indicated that the prognosis for these probable UIP patients appears to be similar to that of typical UIP patients (18). 
Our results are consistent with those of Putman et al. who recently observed that the typical UIP and probable UIP CT patterns were associated with a greater risk of death than was the indeterminate for UIP pattern (8).

The new 2018 international guidelines for CT diagnosis of UIP were developed from several studies that took into account the diagnostic and prognostic value of TB (19-22), together with the presence of signs that can make it difficult to classify ILD, such as the heterogenous appearance of the CT abnormalities and the absence of geographical predominance (23). However, neither the proportions nor the prognoses of the probable UIP and indeterminate for UIP patterns were assessed in these studies.

We found a prevalence of pathological UIP of $91 \%$ for the probable UIP CT pattern and $71 \%$ for the indeterminate UIP CT pattern. The absence of a statistically significant difference could be explained by the lack of patients undergoing pulmonary biopsies. Nevertheless, these results are consistent with previous studies. Chung et al. found a pathological UIP predictive value of $82 \%$ for the probable UIP pattern and 54\% for the indeterminate for UIP pattern (21). Brownell et al. showed that the probability of pathological UIP was 95-97\% in presence of severe and extensive TB on the chest CT-scan (22).

The probable UIP pattern was by definition associated with the presence of peripheral TB, but, more specifically in our study, with a more extensive disease on the chest CT-scan, two well-recognized prognostic factors $(19,20)$. The indeterminate UIP pattern could also include the presence of peripheral TB when the chest CT-scan showed features of lung fibrosis without any specific etiology (7).

We also identified significantly more smokers with lung emphysema in the indeterminate UIP group. Some scans reclassified as indeterminate for UIP with emphysema lesions may have been retrospectively related to both smoking-related interstitial fibrosis (SRIF) and airspace enlargement with fibrosis (AEF) entities (Figure 4) $(24,25)$, which are associated with a slower clinical course than UIP (26). We have not categorized these entities because their diagnostic criteria are not yet sufficiently validated on CT without pathological confirmation. The indeterminate UIP pattern remains a grey area that could include all patients without the three other patterns (typical UIP, probable UIP, and alternative diagnosis), thereby covering SRIF/AEF. However, despite a greater proportion of patients with pulmonary emphysema lesions in the indeterminate UIP group, we observed more respiratory functional impairment 
in the probable UIP than in the indeterminate UIP group. This point supports the nosological distinction and reinforces the value of the new recommendations (7).

This study has some limitations. First, data were missing from the PFTs and hospitalizations records because of the retrospective cohort design. But in view of the objective of the study (i.e. reclassifying CT scans from an old to a new classification), the design could only be retrospective in nature. We have tried to reduce missing data as much as possible. No patient was lost to follow-up and no data were missing for lung transplant-free survival. We therefore believe that our analyses make sense, despite limitations inherent to the study design. Second, our study involved a single tertiary center, which may limit generalization of these results. However, we strived to select only patients whose diagnosis of possible UIP had been validated by MDD. Between 2011 and 2018, there was no substantial change in our institution, either in CT acquisition technique, or in the reading of CT scans. We therefore believe that this MDD reading was reproducible over the 7 years of the study and that such a design is the guarantee of a "real life" study. Finally, only a small number of patients were diagnosed with indeterminate for UIP pattern $(\mathrm{n}=15)$. This limited sample size does not invalidate the results of the multivariate analysis (because there was only two variables in the final model), but it should lead to some caution in interpreting the results. In addition, this group of indeterminate UIP was composed of 8 "early UIP pattern" and 7 "truly indeterminate" patients. Having more than half patients with such a limited disease has undoubtedly accentuated the difference of prognosis with the probable UIP patients, and may therefore constitute a bias.

In conclusion, we have shown that the majority of possible UIP cases correspond to probable UIP while a minority correspond to indeterminate for UIP whose prognosis is significantly better. The probable UIP CT-scan pattern is a powerful prognostic marker when IPF is suspected. These data provide additional evidence of the relevance of the new international guidelines by confirming the value of separating these two CT entities probable UIP and indeterminate for UIP (7). However, research efforts in this area must be continued in order to further refine the non-invasive stratification of patients suspected of having IPF.

\section{Sources of funding}

This study received no specific public, commercial or not-for-profit funds. 


\section{Acknowledgements}

The authors thank Cécile Daoudal, outpatient clinic nurse at our centre, for her contribution and Dr Owen Parkes for editing the English text.

\section{Bibliography}

1. Cottin V, Crestani B, Cadranel J, Cordier J-F, Marchand-Adam S, Prévot G, et al. [French practical guidelines for the diagnosis and management of idiopathic pulmonary fibrosis. 2017 update. Full-length update]. Rev Mal Respir. 2017 Sep 21;

2. King TE, Pardo A, Selman M. Idiopathic pulmonary fibrosis. Lancet Lond Engl. 2011 Dec 3;378(9807):1949-61.

3. King TE, Bradford WZ, Castro-Bernardini S, Fagan EA, Glaspole I, Glassberg MK, et al. A phase 3 trial of pirfenidone in patients with idiopathic pulmonary fibrosis. N Engl J Med. 2014 May 29;370(22):2083-92.

4. Richeldi L, du Bois RM, Raghu G, Azuma A, Brown KK, Costabel U, et al. Efficacy and safety of nintedanib in idiopathic pulmonary fibrosis. N Engl J Med. 2014 May 29;370(22):2071-82.

5. Raghu G, Collard HR, Egan JJ, Martinez FJ, Behr J, Brown KK, et al. An official ATS/ERS/JRS/ALAT statement: idiopathic pulmonary fibrosis: evidence-based guidelines for diagnosis and management. Am J Respir Crit Care Med. 2011 Mar 15;183(6):788-824.

6. Lynch DA, Sverzellati N, Travis WD, Brown KK, Colby TV, Galvin JR, et al. Diagnostic criteria for idiopathic pulmonary fibrosis: a Fleischner Society White Paper. Lancet Respir Med. 2018;6(2):138-53.

7. Raghu G, Remy-Jardin M, Myers JL, Richeldi L, Ryerson CJ, Lederer DJ, et al. Diagnosis of Idiopathic Pulmonary Fibrosis. An Official ATS/ERS/JRS/ALAT Clinical Practice Guideline. Am J Respir Crit Care Med. 2018 Sep 1;198(5):e44-68.

8. Putman RK, Gudmundsson G, Axelsson GT, Hida T, Honda O, Araki T, et al. Imaging Patterns Are Associated with Interstitial Lung Abnormality Progression and Mortality. Am J Respir Crit Care Med. 2019 Jul 15;200(2):175-83.

9. Charlson ME, Pompei P, Ales KL, MacKenzie CR. A new method of classifying prognostic 
comorbidity in longitudinal studies: development and validation. $\mathrm{J}$ Chronic Dis. 1987;40(5):373-83.

10. Miller MR, Hankinson J, Brusasco V, Burgos F, Casaburi R, Coates A, et al. Standardisation of spirometry. Eur Respir J. 2005 Aug;26(2):319-38.

11. Macintyre N, Crapo RO, Viegi G, Johnson DC, van der Grinten CPM, Brusasco V, et al. Standardisation of the single-breath determination of carbon monoxide uptake in the lung. Eur Respir J. 2005 Oct;26(4):720-35.

12. Ley B, Ryerson CJ, Vittinghoff E, Ryu JH, Tomassetti S, Lee JS, et al. A multidimensional index and staging system for idiopathic pulmonary fibrosis. Ann Intern Med. 2012 May 15;156(10):684-91.

13. Ley B, Elicker BM, Hartman TE, Ryerson CJ, Vittinghoff E, Ryu JH, et al. Idiopathic pulmonary fibrosis: CT and risk of death. Radiology. 2014 Nov;273(2):570-9.

14. Hansell DM, Bankier AA, MacMahon H, McLoud TC, Müller NL, Remy J. Fleischner Society: glossary of terms for thoracic imaging. Radiology. 2008 Mar;246(3):697-722.

15. Raghu G, Collard HR, Anstrom KJ, Flaherty KR, Fleming TR, King TE, et al. Idiopathic pulmonary fibrosis: clinically meaningful primary endpoints in phase 3 clinical trials. Am $\mathrm{J}$ Respir Crit Care Med. 2012 May 15;185(10):1044-8.

16. Schmidt SL, Tayob N, Han MK, Zappala C, Kervitsky D, Murray S, et al. Predicting pulmonary fibrosis disease course from past trends in pulmonary function. Chest. 2014 Mar $1 ; 145(3): 579-85$.

17. Durheim MT, Collard HR, Roberts RS, Brown KK, Flaherty KR, King TE, et al. Association of hospital admission and forced vital capacity endpoints with survival in patients with idiopathic pulmonary fibrosis: analysis of a pooled cohort from three clinical trials. Lancet Respir Med. 2015 May;3(5):388-96.

18. Ley B, Collard HR, King TE. Clinical course and prediction of survival in idiopathic pulmonary fibrosis. Am J Respir Crit Care Med. 2011 Feb 15;183(4):431-40.

19. Sumikawa H, Johkoh T, Colby TV, Ichikado K, Suga M, Taniguchi H, et al. Computed tomography findings in pathological usual interstitial pneumonia: relationship to survival. Am J Respir Crit Care Med. 2008 Feb 15;177(4):433-9. 
20. Edey AJ, Devaraj AA, Barker RP, Nicholson AG, Wells AU, Hansell DM. Fibrotic idiopathic interstitial pneumonias: HRCT findings that predict mortality. Eur Radiol. 2011 Aug;21(8):1586-93.

21. Chung JH, Chawla A, Peljto AL, Cool CD, Groshong SD, Talbert JL, et al. CT Scan Findings of Probable Usual Interstitial Pneumonitis Have a High Predictive Value for Histologic Usual Interstitial Pneumonitis. Chest. 2015 Feb;147(2):450-9.

22. Brownell R, Moua T, Henry TS, Elicker BM, White D, Vittinghoff E, et al. The use of pretest probability increases the value of high-resolution CT in diagnosing usual interstitial pneumonia. Thorax. 2017 May;72(5):424-9.

23. Gruden JF. CT in Idiopathic Pulmonary Fibrosis: Diagnosis and Beyond. AJR Am J Roentgenol. 2016 Mar;206(3):495-507.

24. Watanabe Y, Kawabata Y, Kanauchi T, Hoshi E, Kurashima K, Koyama S, et al. Multiple, thin-walled cysts are one of the HRCT features of airspace enlargement with fibrosis. Eur J Radiol. 2015 May;84(5):986-92.

25. Chae KJ, Jin GY, Jung HN, Kwon KS, Choi H, Lee YC, et al. Differentiating SmokingRelated Interstitial Fibrosis (SRIF) from Usual Interstitial Pneumonia (UIP) with Emphysema Using CT Features Based on Pathologically Proven Cases. PloS One. 2016;11(9):e0162231.

26. Otani H, Tanaka T, Murata K, Fukuoka J, Nitta N, Nagatani Y, et al. Smoking-related interstitial fibrosis combined with pulmonary emphysema: computed tomography-pathologic correlative study using lobectomy specimens. Int J Chron Obstruct Pulmon Dis. 2016;11:152132. 


\section{Figure 1: Flow chart}

IPF, idiopathic pulmonary fibrosis; MDD, multidisciplinary discussion; CT, CT scan; UIP, usual interstitial pneumonia

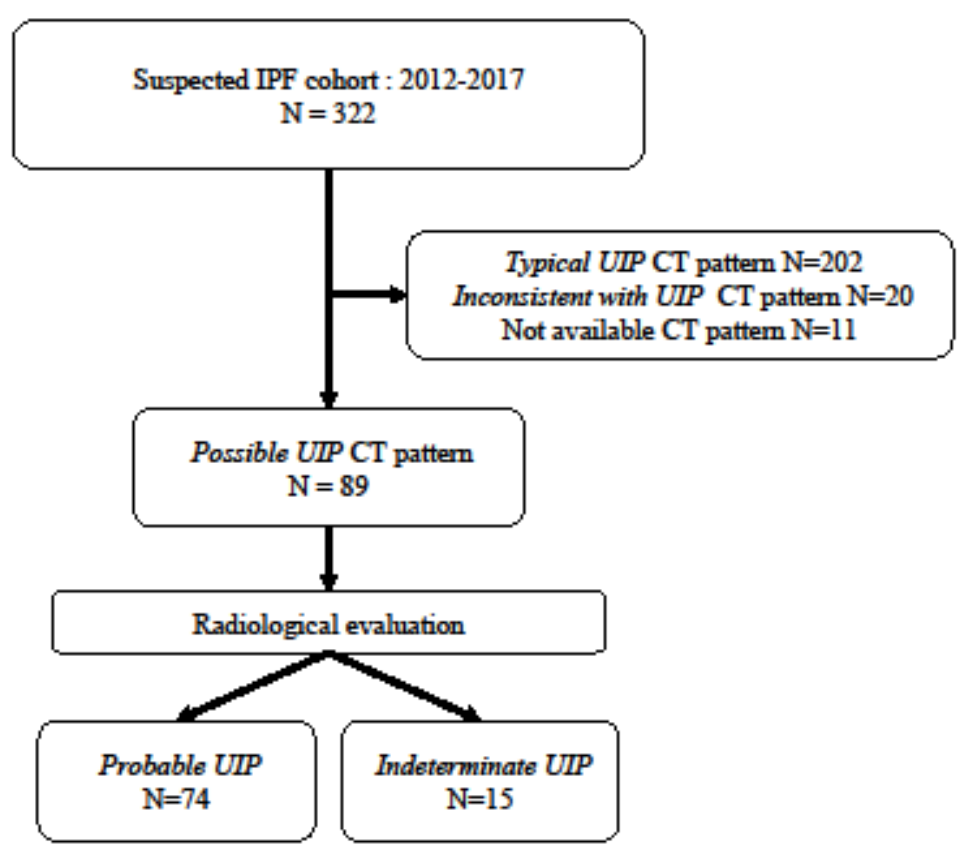

Figure 2: Possible Usual Interstitial Pneumonia (UIP) CT scan (CT) reclassified as Probable UIP.

(A-C) Multiple native axial sections and (D) reconstruction in the sagittal plane, showing reticulations with peripheral traction bronchiolectasis with sub-pleural and basal predominance. Some ground glass opacities are also present in the sub-pleural and basal regions. A UIP was confirmed by surgical lung biopsy. The patient died 30.5 months after diagnosis. 


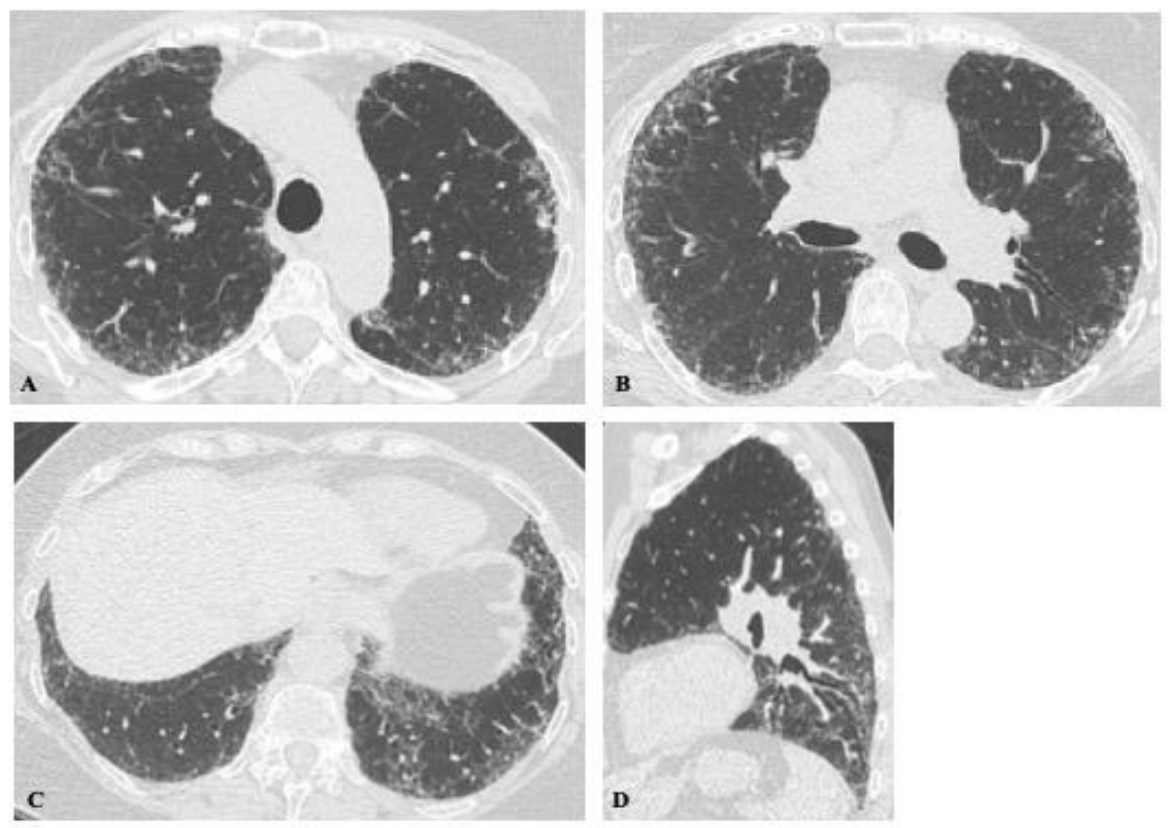

Figure 3: Possible Usual Interstitial Pneumonia (UIP) CT scan (CT) reclassified as indeterminate for UIP.

(A-C) Multiple native axial sections and (D) reconstruction in the sagittal plane, showing reticulations with slightly extended ground glass opacities in sub-pleural and basal regions, without peripheral traction bronchiolectasis. A UIP was confirmed by surgical lung biopsy. The patient is still alive 47 months after diagnosis, with no decline in forced vital capacity (FVC) or hospitalization

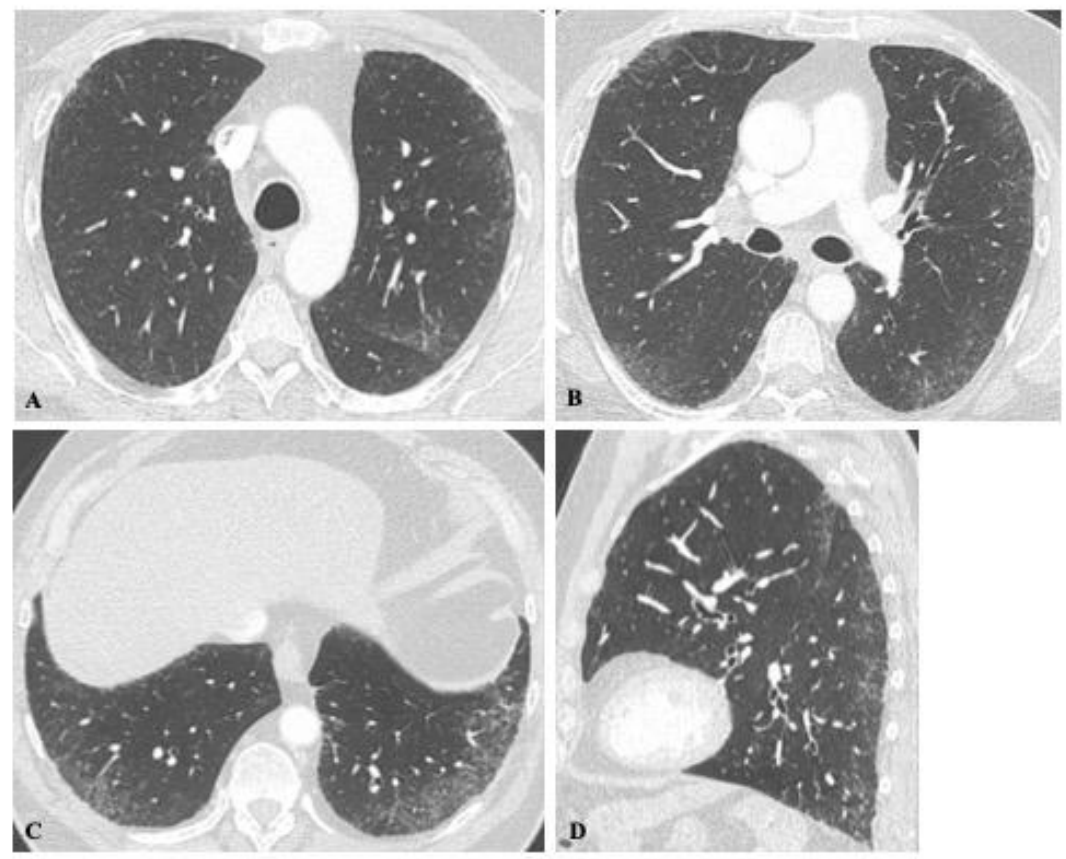

Figure 4: Possible Usual Interstitial Pneumonia (UIP) CT scan (CT) reclassified as indeterminate for UIP.

(A-D) Multiple native axial sections showing mild-to-moderate pulmonary fibrosis with ground glass opacities slightly more extensive than reticulations. The presence of clusters of cysts of varying size and 
shape, with respect of subpleural areas and little architectural distortion, may suggest smoking-related interstitial fibrosis/airspace enlargement with fibrosis (SRIF/AEF) but no surgical lung biopsy was taken. The patient died 58.5 months after diagnosis; progression was slow.
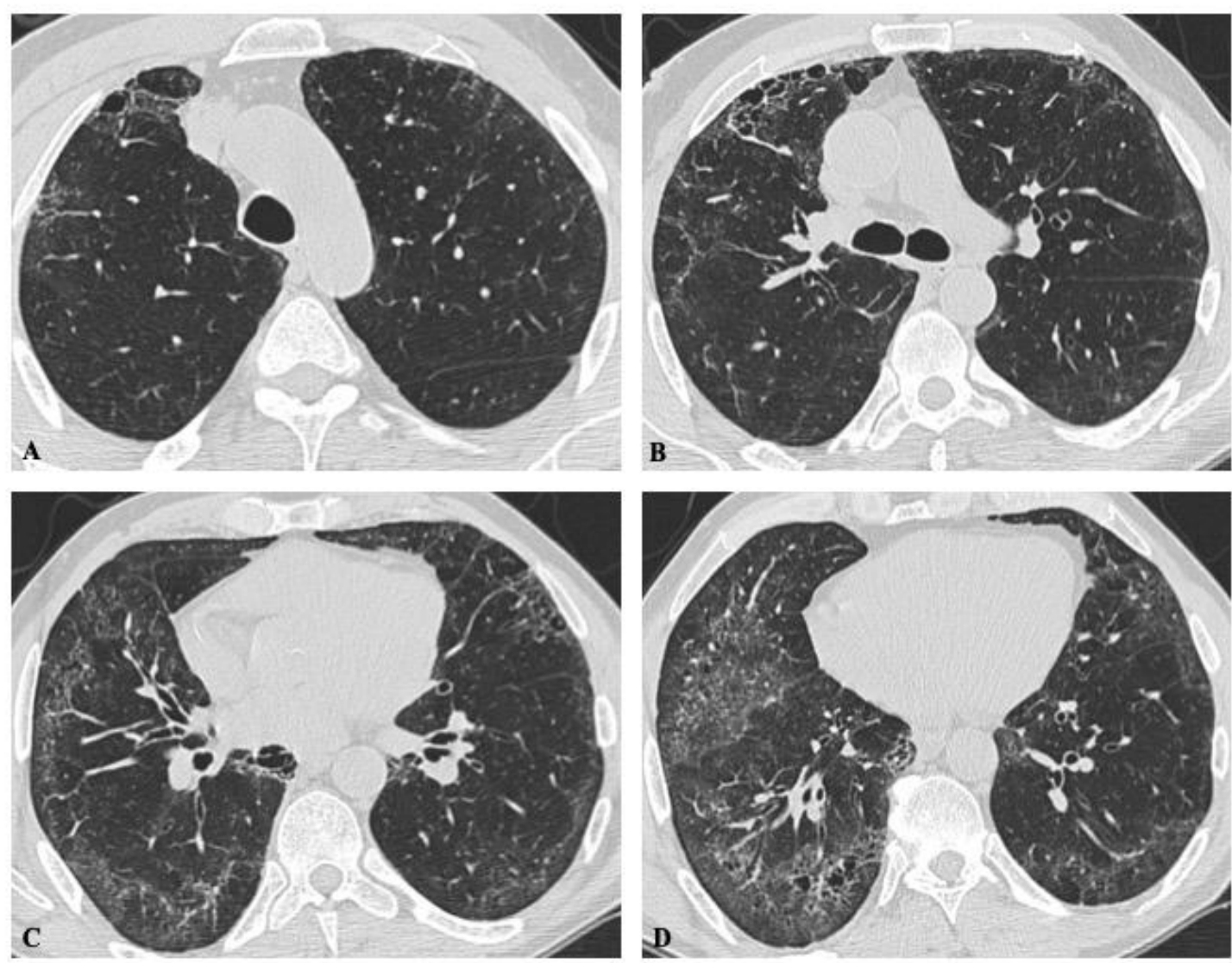

Figure 5: Kaplan-Meier survival curves for composite endpoint (A) and the components: death or lung transplantation (B), decline in FVC $\geq 10 \%(C)$, hospitalization (D), by CTscan group.

FVC, forced vital capacity 

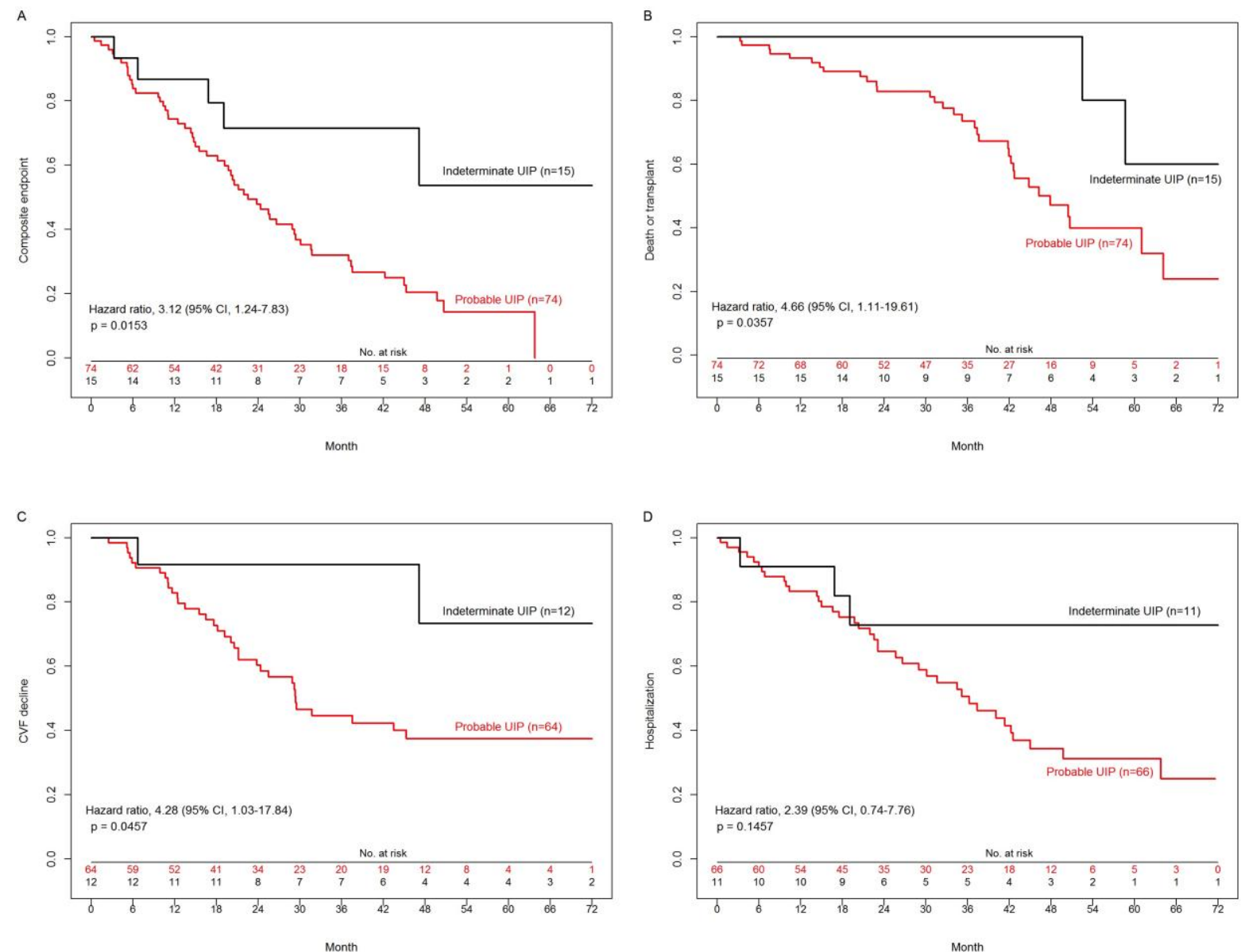

Table 1. Patient characteristics at diagnosis

\begin{tabular}{|l|c|c|c|c|}
\hline Characteristic & $\begin{array}{c}\text { All patients } \\
\text { (possible UIP) } \\
\mathbf{N = 8 9}\end{array}$ & $\begin{array}{c}\text { Probable UIP } \\
\mathbf{N = 7 4}\end{array}$ & $\begin{array}{c}\text { Indeterminate }_{\text {UIP }}^{\#} \\
\mathbf{N = 1 5}\end{array}$ & $\mathbf{p}$ \\
\hline Age (years) & $72.8 \pm 8.2$ & $73.3 \pm 8.3$ & $70.2 \pm 6.9$ & 0.178 \\
\hline Sex (male) & $72(80.9 \%)$ & $59(79.7 \%)$ & $13(86.7 \%)$ & 0.726 \\
\hline Tobacco use & $51(58.6 \%)$ & $38(52.8 \%)$ & $13(86.7 \%)$ & 0.015 \\
\hline Charlson comorbidity score & & & & 0.465 \\
\hline 0 & $40(44.9 \%)$ & $33(44.6 \%)$ & $7(46.7 \%)$ & \\
\hline 1 & $26(29.2 \%)$ & $23(31.1 \%)$ & $3(20.0 \%)$ & \\
\hline 2 & $15(16.9 \%)$ & $10(13.5 \%)$ & $5(33.3 \%)$ & \\
\hline 3 & $6(6.7 \%)$ & $6(8.1 \%)$ & $0(0.0 \%)$ & \\
\hline 4 & $1(1.1 \%)$ & $1(1.4 \%)$ & $0(0.0 \%)$ & \\
\hline 5 & $1(1.1 \%)$ & $1(1.4 \%)$ & $0(0.0 \%)$ & \\
\hline Surgical lung biopsy performed & $41(46.1 \%)$ & $34(45.9 \%)$ & $7(46.7 \%)$ & 0.959 \\
\hline Pathological UIP/surgical lung biopsy & $36 / 41(87.8 \%)$ & $31 / 34(91.2 \%)$ & $5 / 7(71.4 \%)$ & 0.196 \\
\hline Dyspnea (NYHA stages) & $2.0 \pm 1.2$ & $2.2 \pm 1.1$ & $1.1 \pm 1.0$ & $<0.001$ \\
\hline
\end{tabular}




\begin{tabular}{|l|c|c|c|c|}
\hline FVC \% pred & $88.2 \pm 18.7$ & $85.2 \pm 17.3$ & $103.7 \pm 18.6$ & $<0.001$ \\
\hline TLCO \% pred & $52.6 \pm 16.7$ & $50.3 \pm 16.3$ & $65.0 \pm 14.0$ & 0.003 \\
\hline GAP score & $4.0[3.0 ; 4.0]$ & $4.0[3.0 ; 5.0]$ & $3.0[2.0 ; 4.0]$ & $0.041^{*}$ \\
\hline CT total disease extent & $42.2 \pm 19.9$ & $44.8 \pm 19.2$ & $29.7 \pm 18.9$ & 0.006 \\
\hline CT features & & & & \\
\hline Peripheral TB & $81(91.0 \%)$ & $74(100.0 \%)$ & $7(46.7 \%)$ & $<0.001$ \\
\hline Reticulations & $89(100.0 \%)$ & $74(100.0 \%)$ & $15(100.0 \%)$ & NA \\
\hline Ground glass opacity & $77(86.5 \%)$ & $66(89.2 \%)$ & $11(73.3 \%)$ & 0.113 \\
\hline Honeycombing & 0 & 0 & 0 & NA \\
\hline Condensations & $5(5.6 \%)$ & $5(6.8 \%)$ & $0(0.0 \%)$ & 0.584 \\
\hline Mosaic attenuation & $9(10.1 \%)$ & $8(10.8 \%)$ & $1(6.7 \%)$ & 1.000 \\
\hline Emphysema & $19(21.3 \%)$ & $13(17.6 \%)$ & $6(40.0 \%)$ & 0.034 \\
\hline Follow-up time (months) & $25.2 \pm 16.9$ & $23.7 \pm 15.9$ & $34.2 \pm 20.5$ & 0.071 \\
\hline
\end{tabular}

"Indeterminate UIP pattern includes 8 "early UIP pattern" and 7 "truly indeterminate".

UIP, usual interstitial pneumonia; NYHA, New York Heart Association; FVC, forced vital capacity; \% pred, \% of predicted value; TLCO, carbon monoxide lung transfer; GAP score, gender/ age/physiology score; CT, CT scan; TB, traction bronchiectasis; NA, not applicable.

Qualitative variables: number (\%).

Quantitative variables normally distributed: mean \pm standard deviation (Student's $t$ test).

*Quantitative variable not normally distributed: median, interquartile range (Mann-Whitney U-test)

Missing data: Tobacco, n=2; Dyspnea, $n=5$; FVC, $n=1$; TLCO, n=4; GAP score, $n=4$

Table 2. Univariate and multivariate survival analyses for the composite endpoint

HR: hazard ratio; FVC, forced vital capacity; $\%$ pred, $\%$ of predicted value; TLCO, pulmonary transfer of carbon monoxide; GAP score, gender/age/physiology score; CT, CT scan; UIP, usual interstitial pneumonia; TB, traction bronchiectasis

The following variables were included in the multivariate analysis: Charlson comorbidity score, FVC $\%$ pred, TLCO \% pred, probable UIP CT pattern, total CT disease extent. A top-down selection was then made.

Missing data: Tobacco, $n=2 ; \mathrm{FVC}, \mathrm{n}=1 ;$ TLCO, $\mathrm{n}=4$; GAP score, $\mathrm{n}=4$ 


\begin{tabular}{|c|c|c|c|c|}
\hline \multirow{2}{*}{ Variable } & \multicolumn{2}{|c|}{ Univariate analysis } & \multicolumn{2}{|c|}{ Multivariate analysis } \\
\hline & HR $[95 \% \mathrm{CI}]$ & $\mathbf{p}$ & HR $[95 \% \mathrm{CI}]$ & $\mathbf{p}$ \\
\hline Age (for 1 year) & $0.98[0.95 ; 1.01]$ & 0.277 & & \\
\hline Sex male & $1.12[0.58 ; 2.17]$ & 0.728 & & \\
\hline Tobacco use & $1.07[0.64 ; 1.77]$ & 0.798 & & \\
\hline Charlson comorbidity score & & 0.054 & & \\
\hline 0 & 1 & & & \\
\hline 1 & $2.00[1.07 ; 3.72]$ & & & \\
\hline$\geq 2$ & $1.82[0.98 ; 3.38]$ & & & \\
\hline FVC \% pred (for 10\%) & $0.79[0.68 ; 0.91]$ & 0.001 & & \\
\hline TLCO $\%$ pred (for $10 \%$ ) & $0.69[0.58 ; 0.83]$ & $<0.001$ & $0.73[0.61 ; 0.88]$ & $<0.001$ \\
\hline GAP score (for 1 point) & $1.26[1.06 ; 1.50]$ & 0.01 & & \\
\hline Probable UIP CT pattern & $3.12[1.24 ; 7.83]$ & 0.015 & $2.85[1.00 ; 8.10]$ & 0.049 \\
\hline Total CT disease extent (for 10\%) & $1.22[1.06 ; 1.41]$ & 0.004 & 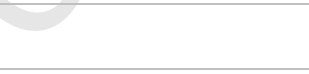 & \\
\hline \multicolumn{5}{|l|}{ CT features } \\
\hline Peripheral TB & $1.27[0.39 ; 4.10]$ & 0.687 & & \\
\hline Ground glass opacity & $2.68[0.97 ; 7.40]$ & 0.057 & & \\
\hline Condensations & $1.08[0.39 ; 2.98]$ & 0.882 & & \\
\hline Mosaic attenuation & $0.80[0.34 ; 1.87]$ & 0.606 & & \\
\hline Emphysema & $1.21[0.66 ; 2.20]$ & 0.542 & & \\
\hline
\end{tabular}

